\title{
Editorial: Late Quaternary Hydrological, Paleoenvironmental and Geomorphological Processes in the Tibetan Plateau and Its Adjacent Areas
}

\author{
Xiangjun Liu ${ }^{1,2 *}$, Xiangzhong $L i^{3 *}$, Zhongping Lai ${ }^{4 *}$ and Feng Cheng ${ }^{5 *}$ \\ ${ }^{1}$ School of Geography and Tourism, Jiaying University, Meizhou, China, ${ }^{2}$ College of Geography and Environmental Science, \\ Northwest Normal University, Lanzhou, China, ${ }^{3}$ Yunnan Key Laboratory of Earth System Science, Yunnan University, Kunming, \\ China, ${ }^{4}$ Guangdong Provincial Key Laboratory of Marine Biotechnology, Shantou University, Shantong, China, ${ }^{5}$ Nevada Bureau \\ of Mines and Geology, Reno, NV, United States
}

Keywords: Tibetan Plateau and its adjacent areas, hydrological and surficial processes, geomorphological processes, paleoenvironments, late quaternary

\section{Editorial on the Research Topic}

Late Quaternary Hydrological, Paleoenvironmental and Geomorphological Processes in the Tibetan Plateau and Its Adjacent Areas

Edited and reviewed by: Steven L. Forman, Baylor University, United States

${ }^{*}$ Correspondence: Xiangjun Liu xiangjunliu@126.com

Xiangzhong $\mathrm{Li}$

xzhli04@163.com

Zhongping Lai zhongping.lai@yahoo.com Feng Cheng cfcf.chengfeng@gmail.com

Specialty section: This article was submitted to Quaternary Science, Geomorphology and Paleoenvironment, a section of the journal

Frontiers in Earth Science

Received: 20 December 2021 Accepted: 11 January 2022

Published: 26 January 2022

Citation:

Liu X, Li X, Lai Z and Cheng F (2022)

Editorial: Late Quaternary

Hydrological, Paleoenvironmental and Geomorphological Processes in the

Tibetan Plateau and lts Adjacent Areas.

Front. Earth Sci. 10:839663. doi: 10.3389/feart.2022.839663
The Tibetan Plateau (TP) has essential impacts on the climate in Asia and even in the Northern Hemisphere. It serves as the headwaters for at least ten large rivers that provide sustaining waters for $>1$ billion people, and is a dust source for downwind areas from the Chinese Loess Plateau to the Pacific Ocean and Greenland. Over the last few decades, many new datasets have been published on the surficial processes of this area during the late Quaternary, including chronologic, organic, and inorganic environmental proxies. The integration of these datasets enable us to have improved understanding of the surficial evolution of the TP and its adjacent areas; and provides insights for current and future climate variability.

This research topic focuses on new advances in late Quaternary hydrological, paleoenvironmental and geomorphological processes in the TP and adjacent areas. This collection includes 20 papers covering research fields such as lake evolution, fluvial and alluvial sedimentation and dating, aeolian processes and chronology, archaeology, salt lake evolution and diagenesis, tectonic processes, and reconstruction of paleoclimate from the applications of the established and new environmental proxies.

Eleven papers in this research topic focused on the geomorphological evolution, lake level variability, salt lake evolution and diagenesis, and archaeological aspects for the TP. Luo et al. dated an archaeological site near Seling Co (at south-central TP) which was previously thought to be 30-40 ka years old. Their Optically Stimulated Luminescence (OSL) dating results indicate the Seling Co site is not earlier than the early Holocene, much younger than the former estimated age. The revised age of Seling Co site is consistent with the warm and humid climate conditions on the central TP during early Holocene. Liu et al. reported that lakes in western inner TP expanded more extensively than those to the east during the early Holocene lake expansion stage. The driving force was the intensification of the Indian summer Monsoon in response to a northward shift of the tropical convergence zone, in combination with the positive phase of the Atlantic Multidecadal Oscillation that resulted in the intensification of southwesterly winds on the southwest flank of the TP. Meanwhile, westerly winds over the TP weakened, resulting in added water vapor transported to the inner TP through the "up-and-over" moisture transport route and then stuck in there. The amount of enhanced precipitation decreased from the southwestern to northeastern inner TP that 
further enhanced high lake levels in western inner TP. Liu et al. found a linear relationship between excess topography and mean erosion rate in drainage basins in southeastern $\mathrm{TP}$, which indicates that hillslope erosion, especially landslides, is the main erosion process. They propose that excess topography is a better metric than slope to describe the spatial distribution of the erosion rates in southeastern TP.

Determining precise ages of lacustrine sediment in TP lakes is difficult due to the complex nature of lake reservoir effects. Cong et al. dated a lacustrine sediment profile near the Zhari Namco (at south-central TP). They found that radiocarbon ages of the same sampling units are divergent between bulk organic matter and grass leaves, and OSL ages, which yield more reliable ages than radiocarbon dating. Yang et al. provide chronology and multiple proxies of an typical aeolian section in Gannan to reconstruct aeolian deposition history in the eastern TP during the Holocene. Their results showed that aeolian deposition occurred in the eastern TP since the early Holocene.

An et al. investigated alluvial sequences in the drainage basins on the northeastern TP based on geomorphic and stratigraphic investigations and OSL chronologies. They found that the development of alluvial fans was driven by glacier activities, and the dynamics of alluvial processes had paleoclimatic origins rather than tectonic. Shen et al. collected two hundred and thirty-four surface pollen samples from moss polsters, top soil, lake surface sediments, shrublands, shrub meadows, meadows, steppes, and deserts in the TP to explore the relationship between modern pollen rain and vegetation. They found main vegetation types can be distinguished by their modern pollen rain. Sun et al. conducted OSL dating of ceramic and tile remains from three ancient cities in Qinghai Lake Basin (at northeastern TP). They found that the warm and humid climate at cal. $2 \mathrm{ka}$ was an important driver of immigration to this region that led to the construction of cities in the Qinghai Lake area during the late Western Han Dynasty. Wende et al. presented human impact on the paleo-environment through the expansion and development of agriculture on the northeast margin of TP, they found that large scale deforestation occurred due to both agricultural practice and pottery production. Primitive natural vegetation was replaced by cultivated land and possibly environmental degradation has occurred due to early grazing. Ma et al. dated a natural section in the salt lake in Qaidam Basin (at northeastern TP) by using OSL dating, they reported the formation periods of the brine lithium deposits and discussed the contemporary paleoenvironmental conditions. $\mathrm{Li}$ et al. measured the chemical composition of fluid inclusions in primary halite that collected from the ISL1A borehole in Qarhan Salt Lake (at southcentral Qaidam Basin), the analysis results showed that $\mathrm{Ca}-\mathrm{Cl}$ type deep brine and tectonic activities have huge impact on the evolution of the Qarhan Salt Lake and the formation of potassium salt.

Five papers in this research topic explored lake level changes, sand dune formations, tectonic processes, and salt mine formations adjacent to the TP. Huang and Chun reconstructed the lake-level variations of Daihai at the marginal region of the East Asian summer monsoon influencing area in north China during the Holocene. Their results revealed the high lake level of Daihai began to develop at $8.1 \mathrm{ka}$ and reached the maximum at $5.2 \mathrm{ka}(\sim 40 \mathrm{~m}$ higher than present), following the enhanced monsoon precipitation during the mid-Holocene. Wang et al. analyzed elements and colors of lacustrine sediments from Chagan Nur at the southern Mongolian Plateau to constrain the lake environmental changes during the Holocene. Their results showed that stable element contents like $\mathrm{Ti}$ are more related to surface erosion and vegetation coverage, and the variations of $\mathrm{Sr}$ are related to lake level changes. Zhu et al. reported that dune sands in the Hexi Corridor are mainly "sediments of insitu rising" that originated from alluvial or fluvial deposits, lacustrine deposits, and aeolian deposits in the erosion zone of the forelands of the Qilian Mountains and the northneighboring deserts. Their research reveals that the interaction between wind and water dynamics is significant in the formation and evolution of aeolian landforms in terms of geomorphic genesis in these arid areas. Li et al. constructed a vertical land motion model based on the latest leveling observations adjacent to the West Qinling orogen and analyzed the modern crustal deformation pattern in this region. They found strain transformation plays a key role in controlling the tectonic uplift in the West Qinling orogen. Hussain et al. combined mineralogy, geochemistry, and fluid inclusion and chlorine stable isotope compositions to discuss the origin and evolution of the Eocene halite in Kohat Basin (in Western Pakistan), they then reconstructed the paleoclimate that was prevailing in Asia during the Eocene.

Four papers in this research topic focus on diatom transfer function to quantitative paleoclimatic reconstruction, loess and Old Red Sand in southern China, and theory for the dynamics of ice age cycles. Zou et al. selected an alpine lake in Southwest China, investigated the seasonal succession of modern diatom assemblages to produce a mean surface water temperature transfer function, and produced a diatom-water depth transfer function by exploring the spatial pattern of surface diatom assemblages with water depth. After being validated by meteorology data, they proposed diatom transfer functions based on modern observations of the same lakes. These functions have a high environmental sensitivity and can be used for the quantitative reconstruction of regional climate change on various timescales. Fan et al. used grain size data and quartz grain surface microtexture observations to identify the provenance for the Xiashu loess in southern China, they concluded that floodplains in the lower reaches of the Yangtze River, the alluvial plains of the Huai River, and the Yellow River to the north are the dominant source areas. Fan et al. studied the origin and paleoenvironmental significance of the Old Red Sand (ORS) on the southeast coast of China. They reported that the grain size of the ORS shows typical aeolian features, the quartz grain surface microtexture of the ORS shows both aeolian features and subaqueous environment characteristics. At last, Lai et al. proposed a new theory for the dynamics of ice age cycles focusing on the saw-tooth patterns and related changes in the energy balance of the Earth. By analyzing global temperature archives 
reconstructed from various proxies, they suggest the cooling of ice ages is associated with slow Northern Hemisphere high-latitude processes, while deglacial warming is associated with fast heat release from the deep ocean. This "bimodal forcing" hypothesis poses questions to the previous single forcing theories which suggest the control of Northern Hemisphere high latitude areas and pave a new way to understand the dynamics of ice ages.

\section{AUTHOR CONTRIBUTIONS}

All authors listed have made a substantial, direct, and intellectual contribution to the work and approved it for publication.

\section{FUNDING}

We acknowledge the supports from the Second Tibetan Plateau Scientific Expedition and Research Program (2019QZKK0202) and the National Natural Science Foundation of China (41671006).

\section{ACKNOWLEDGMENTS}

We appreciate the Editorial office of Frontiers in Earth Science for their timely support during organizing and managing the topic, and all the reviewers for their selfless contributions during the reviewing processes that substantially improved the qualities of these published papers.

Conflict of Interest: The authors declare that the research was conducted in the absence of any commercial or financial relationships that could be construed as a potential conflict of interest.

Publisher's Note: All claims expressed in this article are solely those of the authors and do not necessarily represent those of their affiliated organizations, or those of the publisher, the editors and the reviewers. Any product that may be evaluated in this article, or claim that may be made by its manufacturer, is not guaranteed or endorsed by the publisher.

Copyright (C) $2022 \mathrm{Liu}, \mathrm{Li}$, Lai and Cheng. This is an open-access article distributed under the terms of the Creative Commons Attribution License (CC BY). The use, distribution or reproduction in other forums is permitted, provided the original author(s) and the copyright owner(s) are credited and that the original publication in this journal is cited, in accordance with accepted academic practice. No use, distribution or reproduction is permitted which does not comply with these terms. 